\title{
Requirements of the Smart Factory System: A Survey and Perspective
}

\author{
Mohammed M. Mabkhot ${ }^{1, *(1)}$, Abdulrahman M. Al-Ahmari ${ }^{1,2}{ }^{\text {, }}$ Bashir Salah ${ }^{1}$ and \\ Hisham Alkhalefah ${ }^{2}$ \\ 1 Department of Industrial Engineering, College of Engineering, King Saud University, KSU, \\ Riyadh 11421, Saudi Arabia; alahmari@ksu.edu.sa (A.M.A.-A.); bsalah@ksu.edu.sa (B.S.) \\ 2 Raytheon Chair for System Engineering, Advanced Manufacturing Institute, King Saud University, \\ Riyadh 11421, Saudi Arabia; halkhalefah@ksu.edu.sa \\ * Correspondence: mmabkhot@ksu.edu.sa; Tel.: +966-592-961-690
}

Received: 19 April 2018; Accepted: 25 May 2018; Published: 01 June 2018

\begin{abstract}
With the development of Industry 4.0 and the emergence of the smart factory concept, the traditional philosophy of manufacturing systems will change. The smart factory introduces changes to the factors and elements of traditional manufacturing systems and incorporates the current requirements of smart systems so that it can compete in the future. An increasing amount of research in both academia and industry is dedicated to transitioning the concept of the smart factory from theory to practice. The purpose of the current research is to highlight the perspectives that shape the smart factory and to suggest approaches and technical support to enable the realization of those perspectives. This paper fills this gap by identifying and analyzing research on smart factories. We suggest a framework to analyze existing research and investigate the elements and features of smart factory systems.
\end{abstract}

Keywords: smart factory; Industry 4.0; cyber-physical system; smart manufacturing; cloud manufacturing

\section{Introduction}

Manufacturing companies are currently confronted with multifaceted challenges created by rapid technological changes, i.e., short product life cycles, volatile demand and highly customized products [1]. To compete in future markets, manufacturing companies should be able to produce small batch sizes of a product-or even a single item - in a timely and cost-effective manner, and they should have sufficient functionality, scalability, and connectivity with customers and suppliers to meet these requirements [2]. In addition, to meet such challenges, systems will become more complex and difficult to monitor and control. Traditional manufacturing systems (flexible manufacturing systems, dedicated production lines, etc.) will be unable to compete in future markets [3].

Many technologies have recently appeared and evolved, including Cyber-Physical Systems (CPS), Internet of Things (IoT), Internet of Services (IoS), Big Data, Cloud Computing, Semantic Web, and virtualization [4]. Industry 4.0 (I4.0) has emerged as a new industrialization concept that exploits these new technologies to cope with the challenges set forth above. The smart factory is the heart of I4.0 [5]. The smart factory integrates these technologies to improve performance, quality, controllability, and transparency of manufacturing processes. In the smart factory, the system is context-aware and helps people and machines execute their tasks based on information from both physical and virtual worlds. Components of the system can negotiate with each other and with other factory components to either request or offer functions [6].

Since the announcement of I4.0, substantial research has been dedicated to initiate smart factories, investigate their features, design their key enablers, and implement them on the ground [7]. 
Unfortunately, there is no paper focused on the smart factory and identify works on such system or shed light on research interests that help to understand components of such system. Although investigating existing works to answer a question of what are the requirements of designing such system, this paper fills in this gap by identifying and analyzing works on the smart factory. We investigate existing research to answer this question. We provide a classification of existing works in the smart factory system, discuss their contribution toward such system, and show that interesting and challenging research directions are still worth investigating.

The rest of paper is organized as follows. Section 2 introduces I4.0 and its key components. Section 3 introduces the smart factory system as a new paradigm. In this section, the requirements of a smart factory system are itemized, and the existing literature is classified. Section 4 analyzes the existing literature with respect to the suggested requirements. Section 5 provides discussion and proposes several research directions. Section 6 concludes the paper.

\section{Industry 4.0: An Overview}

Since the invention of the mechanical capability enabled by thermal and kinetic energy at the end of the 18th century, the evolution of the industrial sector has reshaped our lives. The resulting inventions are known as the first industrial revolution. Consequently, inventions through the mid-19th century, specifically the emergence of the electrical technological production system constituted the second industrial revolution and reshaped the industry by enabling mass production [8]. In 1969, the use of the Programmable Logical Controller (PLC) enabled synergy between information technology and electronics, facilitating an increase in industrial automation that continues to this day. This development is recognized as the third industrial revolution $[9,10]$.

Today, manufacturing companies face multifaceted challenges such as a shortened innovation and technology life cycle and a demand for custom products at the cost of large-scale production [11]. In addition, the presence of industry in emerging countries has created the competitive pressure of the global market. Such industrial companies have the capacity for technological absorption and present as manufacturing companies with low operating costs that will pull up the market away from developed countries (i.e., Germany, the US, and Italy) [12].

The government and manufacturing sectors, specifically in Germany, are attempting to secure their market share through inventions toward the fourth industrial revolution a so-called I4.0. I4.0 will exploit existing advances in information technology, communications, automation and beyond to form a new industrial era $[13,14]$. The goal is to create a national industrial sector with the ability to compete in the global market by creating high value-added products through the innovation of products and services. Innovations will empower companies by giving them a uniquely competitive advantage of increased efficiency, resource utilization and responsiveness to the needs of both customers and society [15].

Other countries are aware of the aforementioned challenges and some of them have a vision similar to that of I4.0. Examples of such visions include Fabricca Intelligente in Italy, Flanders Make in Belgium, the Smart Manufacturing Leadership Coalition in the USA [16], Made in China in China and Made in India in India.

\subsection{Definition of Industry 4.0}

The term I4.0 entered use at the beginning of this decade to describe the next industrial revolution. Sanders et al. [17] defined I4.0 as "the fourth industrial revolution applying the principles of cyber-physical systems (CPS), Internet and future-oriented technologies and smart systems with enhanced human-machine interaction paradigms". Wolter et al. [18] expanded this view to the entire value chain from the business model to low-level service offerings and work in process, defining I4.0 as "( . . ).The resulting consequences have also an effect on the value chain, the business models, the downstream services and the work in progress". Akeson [19] highlighted the need for customization as "( ... ). It is geared towards increasingly individualized customer requirements". These definitions claimed that I4.0 is a matter of 
digitalization and communication interaction, they did not show how these potential enablers can be used on the shop floor of promising I4.0 manufacturing systems.

Brettel et al. [20] emphasized shop floor components, indicating that "Industry 4.0 focuses on the establishment of intelligent products and production processes". These authors view I4.0 as a digitalization of product and processes through increased intelligence. McKinsey and Company defined I4.0 in a manner that added the power of big data, cloud computing and the wide-spread implementation of new technologies " (. . ) driven by four disruptions: the astonishing rise in data volumes, computational power, (... ) and improvements in transferring digital instructions to the physical world, such as advanced robotics and 3-D printing". Baums, Hofman and Rüsch, Balasingham and Fedral Ministry of Education and Research [21-24] agreed that autonomous system components and decentralized control systems are essential enablers of I4.0: “( . . ) The value networks are subject to decentralized control while system elements (like manufacturing facilities or transport vehicles) are making autonomous decisions (autonomous and decentralized decision making".

However, most researchers agreed that I4.0 is the fourth revolution and will change the concept of manufacturing. I4.0 is a new concept that is in the predictive stage, offering an opportunity for companies and institutions to shape the future given that a clear and consistent definition of I4.0 is lacking. In this paper, we consider the definition of I4.0 by Herman et al. [13] as a "collective term for technologies and concepts of value chain organization. Within the modular structured Smart Factories of I4.0, CPS monitor physical processes, create a virtual copy of the physical world and make decentralized decisions. Over the IoT, CPS communicate and cooperate with each other and humans in real time. Via the IoS, both internal and cross-organizational services are offered and utilized by participants of the value chain". We believe that this definition considers most of the enablers of I4.0, including shop floor components with a modular structure, autonomy and decentralization, CPS, virtual systems, IoT, and IoS. We will explain these enablers in the following section.

\subsection{Key Components of I4.0}

As noted above, I4.0 is a collective term for technologies that will enable the manifestation of smart industry. Herman et al. and Yao et al. $[13,25]$ view these technologies, which include big data, cloud computing, IoT, CPS, and the smart factory, as components of I4.0.

\subsubsection{Big Data}

Big data is structured, unstructured, and raw data stored in multiple disparate formats. Traditional databases store only structured data consisting of letters and numbers, but in this era of big data, there is a need to store semi-structured and unstructured data [26]. With the increased use of the Internet and social networks that has emerged in the last two decades, the amount of data has massively increased [27]. According to a new report from IBM Marketing Cloud, $90 \%$ of the data existing in the world up to the end of 2016 was created in 2015 and 2016 at a rate of 2.5 quintillion bytes of data a day [28]. A big data repository offers substantial potential to store and retrieve the required data at any level of the value chain of the manufacturing system. This potential will provide companies with many benefits, including identifying the root causes of failures in real time, fully understanding the potential of data-driven marketing, and generating customer offers based on their buying habits and requirements. The implementation of big data in I4.0 creates many challenges, including data acquisition, data transformation, data integration and modeling, and cloud manufacturing [29].

\subsubsection{Cloud Manufacturing}

Cloud Manufacturing (CM) is an industrial version of cloud computing. $\mathrm{CM}$ is a service-oriented networked manufacturing model that transforms manufacturing resources and capabilities to manufacturing services [30]. CM is a form of the IoS in a manufacturing system. In such a platform, services are offered and combined into value-added services by various suppliers. Manufacturing services are communicated to both users and consumers, who access those services via various 
channels [31]. Manufacturing software should be deployed in the cloud to enable the offering of such services. Manufacturing services should be deployed in various models, including the public, private, community and hybrid clouds [30]. Each cloud provides consumers with a different service. For example, the end-user consumer can find required product offers in a public cloud, and an organization employee can find services and infrastructure provided from their organization or its specified service provider in a private cloud. Big data will be used to offer the best services to satisfy consumer requirements and expectations.

\subsubsection{Internet of Things}

The IoT is the infrastructure of interconnection among objects. In manufacturing systems, each device is embedded with electronic software, sensors, and actuators and is connected to Internet networks [26]. The IoT enables manufacturing devices to exchange data within manufacturing devices and between manufacturing devices and their service providers or consumers. From the technical point of view, we can describe the IoT as a combination of sensors such as RFID, other communication devices (i.e., embedded computers), CM applications, Enterprise Resource Planning (ERP) integration and business intelligence technology. Sensors are embedded in physical objects such as vehicles and heavy equipment (cranes, automated guided vehicles (AGVs), loaders), machines, and robots [32]. A standard communication protocol is an essential enabler of IoT deployment (cf. Section 4.1). The communication and foundation of the IoT are the inspiration for CPS.

\subsubsection{Cyber-Physical System}

The foundation of big data, the accessibility potential of the IoT and the analytics promised by CM make it possible to integrate the physical and virtual worlds. This integration is known as CPS, which integrates computations with physical processes. Embedded computers and networks monitor and control physical processes, usually with feedback loops in which physical processes affect computations and vice versa [23]. This means that information about manufacturing components on the shop floor (i.e., machines, robots) and their corresponding modules in virtual space are synchronized. CPS manage big data and leverage the interconnectivity of manufacturing components to achieve the goal of intelligent, resilient and self-adaptable components [33]. To pave a way to CPS, researchers focused on developing a Digital Twin (DT). More details about DT will be discussed in Section 4.7. Such components are transforming the concept of the traditional factory toward a smart factory.

\subsubsection{Smart Factory}

The implementation of the IoT and CPS technologies in manufacturing systems has added new capabilities, enabling the management of complex and flexible systems to satisfy rapid changes in production volumes and customization [26]. New technologies provide efficient virtual and real manufacturing systems, increasing context-awareness to assist people and machines in the perfect execution of their tasks [34]. Awareness refers to the availability of knowledge of system components, the history of system performance and the ongoing state of the system. This type of manufacturing system is known as a smart factory. The term "smart factory" is used in research on I4.0. Researchers consider the smart factory as the heart of I4.0.

The literature has proposed many definitions of the term "smart factory". We select a comprehensive definition by Radziwon et al. [35], who defined the smart factory as "a manufacturing solution that provides such flexible and adaptive production processes that will solve problems arising on a production facility with dynamic and rapidly changing boundary conditions in a world of increasing complexity. This special solution could, on one hand, be related to automation, understood as a combination of software, hardware and/or mechanics, which should lead to optimization of manufacturing resulting in reduction of unnecessary labor and waste of resource. On the other hand, it could be seen in a perspective of collaboration between different industrial and nonindustrial partners, where the smartness comes from forming a dynamic organization". They highlighted the potential of the system, describing its enablers and the cooperative 
behavior of different partners that offer this potential. The term "smart factory" has synonyms in various countries (e.g., cloud manufacturing, smart industries, advanced manufacturing, smart production, ubiquitous manufacturing, big data and digital manufacturing) [16]. In the following sections, we will focus on the smart factory.

\section{Requirements of a Smart Factory}

In this section, a framework is suggested to help identifying and describing the smart factory system. We suggest requirements that a factory should fulfil to increase its smartness. Most of the literature is focused on the design principles of the smart factory. We have tried to look to the future as possible, but emphasis is concentrated on what is possible today with existing technology. We considered these principles, which are presented below, as guidelines for our suggested requirements.

\subsection{Design Principles of a Smart Factory}

The design principles of a smart factory help designers build new smart factories or upgrade existing traditional factories to be smart. Herman et al. [13] presented an overview of these principles in terms of the general scope of I4.0. In this section, we will investigate and analyze these principles in terms of the scope of the smart factory. These principles are illustrated as follows:

P1. Modularity: This refers to the design of system components. Modularity can be defined as the capability of system components to be separated and combined easily and quickly. System components are loosely coupled and can be reconfigured on a plug-and-play principle [13]. For example, modules can be added, rearranged or relocated in the production line on time (cf. Section 4.3). The smart factory should possess high modularity, allowing the rapid integration of modules that can be supplied by multiple vendors [36]. Modularity enables the real-time capability to allow the system to respond to changing customer requirements and to overcome internal system malfunctions.

P2. Interoperability: This refers to both the ability to share technical information within system components, including products and to the ability to share business information between manufacturing enterprises and customers. CPS enable connection over the IoT and the IoS. Standardized mechanical, electrical and communication information is essential to enhancing interoperability [37]. In communication, semantic technologies show promise in enabling interoperability for the smart factory, and many ontologies have been developed around this issue [38]. Another crucial enabler of interoperability is a controller that can be integrated more flexibly with other systems and is generally quicker to pick up new interoperability features such as OPC UA. Smart PLCs have an advantage in this regard, allowing greater integration between the PLC and IT programs [39].

P3. Decentralization: System elements (modules, material handling, products, etc.) will make decisions on their own, unsubordinated to a control unit. A decision will be made autonomously in real time without violating the overall organizational goal. In these systems, employees make decisions about ordinary matters on time and change their strategy and direction according to the change in business situations and environments [40]. Embedded computers enable autonomous CPS to interact with their environment via sensors and actuators (cf. Section 4.5). Such interaction will adapt processes to each individual order, enabling low-cost, custom-tailored products [37].

P4. Virtualization: This refers to both creating an artificial factory environment with CPS similar to the actual environment and to being able to monitor and simulate physical processes. Information transparency in CPS and the aggregation of sensor data enable the creation of such an environment [41]. A virtual system is used to monitor and control its physical aspect, which sends data to update its virtual model in real time [5]. A virtual system enables the implementation of designs, creating digital prototypes that are very similar to the real ones [42]. 
The design can be checked, modified, and tested prior to its order into the physical system. In addition, a virtual system is helpful for other issues such as training the workforce, guiding the workforce while performing manual processes, diagnosing, and predicting faults and guiding maintenance tasks to fix malfunctions. Virtual reality and augmented reality combination with mobile devices provide customers more insight into the detailed design of their products and allow them to track the manufacturing process.

P5. Service orientation: This refers to the idea that manufacturing industries will shift from selling products to selling products and services. Manufacturing industries are becoming service providers as their products have reached competitive equality. Using such a strategy, a product can be sold to customers with almost no margin or profit. Instead of focusing on profit from selling the product, organizations focus on selling the service [43]. Products and services will be integrated and sold together. Today, manufacturing industries outsource some of their services, focusing on their core businesses. In the smart factory, manufacturing industries will move towards outsourcing some of their processes and concentrating on their core processes [26]. Such a strategy encourages innovation in the improvement of core process(s) in which the resources are concentrated and will not disperse. In turn, a manufacturing industry will sell its core process(s) as a service to another industry. CM describes an infrastructure that uses the Internet as a medium for offering and selling services, where cloud computing plays an important role in enabling the on-demand provision of services [25].

P6. Real-time capability (responsiveness): This refers to the ability of the system to respond to changes on time, such as changes in customer requirements or the status of the internal production system (e.g., malfunctions and resource failures). To respond to customer requirements, information should be accessed and analyzed in real time [23]. The system will investigate the possibility of meeting requirements using existing resources through reconfiguration or cooperation with other factories via CPS and CM requesting services (processes) that are not available in the factory [44]. The system should have a sufficient degree of modularity to accomplish such a reconfiguration. Responses to internal changes, monitoring and controlling should be in real time. Disturbances should be detected on time, and the system should have the ability to recover rapidly.

\subsection{Requirements of a Smart Factory}

We review existing perspectives towards smart factories in the research and manufacturing sectors to understand and elicit requirements. We add requirements that reflect our perspective on the smart factory system. It is worth mention, Gorecky et al. [45] presented six requirements in a general overview of the smart factory system that are related to modular structure of such system. To the best of our knowledge, this paper is the first attempt to collect and present the requirements in this form. Table 1 presents these requirements. Table 1 also analyses the suggested requirements in terms of the design principles of the smart factory presented in Section 3.1.

\subsection{Literature Survey}

This section highlights the scope of the survey and provide readers with existing literature.

\subsubsection{Scope of the Survey}

In this paper, the existing literature on smart factory systems is analyzed with the suggested requirements. In addition, an investigation of the current state of technologies with respect to the enablers of the smart factory is presented. To the best of the author's knowledge, no paper has surveyed and suggested comprehensive requirements for the smart factory and analyzed existing research on these requirements. This paper emphasizes the literature that contributes to the formation of the future smart factory in the form of technical enablers, software solutions, surveys, tutorials, or perspective of the smart factory system. 
Table 1. Requirements for a smart factory.

\begin{tabular}{|c|c|c|c|}
\hline Req. & Requirements & Interpretation & Prin. \\
\hline $\mathbf{R} 1$ & $\begin{array}{l}\text { Modular machine tools or } \\
\text { workstations: }\end{array}$ & $\begin{array}{l}\text { These refer to the flexibility of machines and work } \\
\text { stations to be reconfigured in terms of changing the shop } \\
\text { floor layout and adjusting the process function. }\end{array}$ & $\begin{array}{l}\text { P1 } \\
\text { P6 }\end{array}$ \\
\hline $\mathbf{R 2}$ & $\begin{array}{l}\text { Modular material handling } \\
\text { equipment: }\end{array}$ & $\begin{array}{l}\text { This refers to the possibility of reconfiguring material } \\
\text { handling equipment (i.e., conveyors, AGVs) on the shop } \\
\text { floor or changing equipment capability to transfer the } \\
\text { required product. }\end{array}$ & $\begin{array}{l}\text { P1 } \\
\text { P3 }\end{array}$ \\
\hline R3 & Multi-skilled workforce: & $\begin{array}{l}\text { This refers to the ability of the workforce to perform } \\
\text { several types of tasks, including decision making, } \\
\text { supervision, maintenance, programming or performing } \\
\text { a manual assembly or process. }\end{array}$ & P1 \\
\hline R4 & Reconfigurable fixture: & $\begin{array}{l}\text { This refers to the adjustability of a fixture to hold set(s) } \\
\text { of parts or products. }\end{array}$ & P1 \\
\hline R5 & Reconfigurable tools: & $\begin{array}{l}\text { This refers to the capability of tools to be used in } \\
\text { different tasks (i.e., tightening different sizes of bolts). }\end{array}$ & $\begin{array}{l}\text { P1 } \\
\text { P2 }\end{array}$ \\
\hline R6 & Standard infrastructure: & $\begin{array}{l}\text { This refers to the use of a standard supply infrastructure } \\
\text { that connects system components to all supply layers } \\
\text { (i.e., pressurized air, current, Ethernet). System } \\
\text { components can be supplied by different vendors. }\end{array}$ & $\begin{array}{l}\text { P1 } \\
\text { P6 }\end{array}$ \\
\hline R7 & $\begin{array}{l}\text { Standard communication and } \\
\text { CPS: }\end{array}$ & $\begin{array}{l}\text { Throughout a standardized communication protocol, } \\
\text { information can be reordered, enriched, and saved in the } \\
\text { integration layer. }\end{array}$ & P2 \\
\hline R8 & Embedded computer: & $\begin{array}{l}\text { Each physical module should have an embedded } \\
\text { computer to enable autonomous decisions and retrieve } \\
\text { required information from cloud computing via CPS. }\end{array}$ & $\begin{array}{l}\text { P2 } \\
\text { P3 }\end{array}$ \\
\hline R9 & $\begin{array}{l}\text { Sharing meaningful } \\
\text { information: }\end{array}$ & $\begin{array}{l}\text { This refers to a common framework that allows data to } \\
\text { be shared and reused across application, enterprise, and } \\
\text { factory boundaries in a meaningful manner (i.e., } \\
\text { Semantic Web technology). }\end{array}$ & P2 \\
\hline R10 & Secure communication: & $\begin{array}{l}\text { This refers to authenticating access requests for } \\
\text { information in cloud computing. }\end{array}$ & P2 \\
\hline R11 & Collaborative behavior: & $\begin{array}{l}\text { System components (agents) work together to } \\
\text { accomplish system goals. }\end{array}$ & P2 \\
\hline R12 & $\begin{array}{l}\text { Modular and decentralized } \\
\text { control architecture: }\end{array}$ & $\begin{array}{l}\text { The control system should identify the physical module } \\
\text { plugged into the system and automatically upload its } \\
\text { control module from cloud computing without the need } \\
\text { for human intervention. }\end{array}$ & P3 \\
\hline R13 & Smart product: & $\begin{array}{l}\text { A product should identify itself to the modules, } \\
\text { providing all information required to accomplish its } \\
\text { process on module. RFIDs are attached to the product so } \\
\text { that product-related information can be accessed. }\end{array}$ & P3 \\
\hline R14 & Virtual system builder: & $\begin{array}{l}\text { A software package or virtual repository that works as } \\
\text { an engine to run the virtual system, enabling effective } \\
\text { simulation. }\end{array}$ & $\mathbf{P 4}$ \\
\hline R15 & Capturing actual factory: & $\begin{array}{l}\text { The shop floor should be captured very near to the real } \\
\text { system, i.e., using } 360^{\circ} \text { cameras. }\end{array}$ & $\mathbf{P 4}$ \\
\hline R16 & Virtual reader: & $\begin{array}{l}\text { This provides a virtual system with online data from } \\
\text { shop-floor sensors. }\end{array}$ & $\mathbf{P 4}$ \\
\hline R17 & Virtual interfaces with CPS: & $\begin{array}{l}\text { These are interfaces that can retrieve and store } \\
\text { information from CPS and its related knowledge bases, } \\
\text { enabling online simulation and diagnosing assistance. }\end{array}$ & P4 \\
\hline R18 & $\begin{array}{l}\text { Standardized virtual } \\
\text { modelling language: }\end{array}$ & $\begin{array}{l}\text { This enables manufacturers building a virtual module } \\
\text { corresponding to the physical module to be able to load } \\
\text { the virtual module from cloud manufacturing and } \\
\text { automatically integrate it with the virtual system. }\end{array}$ & P4 \\
\hline R19 & After-sale services: & $\begin{array}{l}\text { This refers to tracing products and offering services over } \\
\text { the product life cycle. }\end{array}$ & P5 \\
\hline $\mathbf{R} 20$ & $\begin{array}{l}\text { Offering core processes as } \\
\text { services. }\end{array}$ & $\begin{array}{l}\text { The factory can offer its core function(s) to external } \\
\text { factories or other internal factories. }\end{array}$ & P5 \\
\hline
\end{tabular}


Table 1. Cont.

\begin{tabular}{cllc}
\hline Req. & \multicolumn{1}{c}{ Requirements } & \multicolumn{1}{c}{ Interpretation } & Prin. \\
\hline R21 & Cloud computing: & $\begin{array}{l}\text { This refers to sharing product service and factory } \\
\text { functions via cloud computing. }\end{array}$ & P5 \\
\hline R22 & Cloud connection: & $\begin{array}{l}\text { This refers to access to the requirements of both } \\
\text { customers and service suppliers. }\end{array}$ & P6 \\
\hline R23 & Online data analysis: & $\begin{array}{l}\text { This refers to transferring customer requirements to } \\
\text { products and investigating manufacturability using } \\
\text { existing resource or outsourcing services. }\end{array}$ & P6 \\
\hline R24 & $\begin{array}{l}\text { Customization and real-time } \\
\text { capability: }\end{array}$ & $\begin{array}{l}\text { This refers to the ability to respond in real time and for } \\
\text { manufacturing to order even a single unit. }\end{array}$ & P6 \\
\hline R25 & $\begin{array}{l}\text { Online monitoring and } \\
\text { control: }\end{array}$ & $\begin{array}{l}\text { The systems are monitored and controlled in real time } \\
\text { using diagnostic and reactive decision-making. }\end{array}$ & P6 \\
\hline R26 & $\begin{array}{l}\text { Healability: } \\
\text { Notations: } \text { Req. Requirements. Prin. Principles }\end{array}$ & $\begin{array}{l}\text { The system should be able to recover from disturbances } \\
\text { in real time. }\end{array}$ & P6 \\
\hline
\end{tabular}

\subsubsection{Literature Analysis}

We used several databases in our literature search, including ScienceDirect, IEEE Explore, SpringerLink, Emerald Insight, Digital Library and the Taylor and Francis Library. We looked for papers using the following keywords: "Smart factory", "Intelligent factory", "Brilliant factory", "Digital factory", "Ubiquitous manufacturing", "Cloud manufacturing", "Wisdom manufacturing", "Intelligent production" and "Intelligent industry". We found 428 articles related to our survey. To refine the references and keep to the survey scope, we read abstract, introduction, and conclusion. Finally, we ended up with 94 references. These references are classified into eight categories in Figure 1 based on the research topic and interest.

\begin{tabular}{|c|c|c|c|c|c|c|c|}
\hline 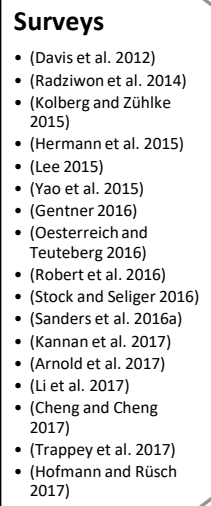 & $\begin{array}{l}\text { Perspecti } \\
\text { ves } \\
\text { - (Dugenske } \\
\text { and Louchez } \\
\text { 2014) } \\
\text { - (Erol et al. } \\
\text { 2016) } \\
\text { - (Qin et al. } \\
\text { 2016) } \\
\text { - (Rauch et al. } \\
\text { 2016) } \\
\text { - (Vogel-Heuser } \\
\text { and Hess } \\
\text { 2016) }\end{array}$ & $\begin{array}{l}\text { System } \\
\text { Design } \\
\text { - (Gorecky } \\
\text { et al. 2016) } \\
\text { - (Weyer et } \\
\text { al. 2015) } \\
\text { - (Syberfeldt } \\
\text { et al. 2017) } \\
\text { - Andersen } \\
\text { et al. 2017 } \\
\text { - Madsen et } \\
\text { al. 2017 } \\
\text { - Nardello et } \\
\text { al. 2017 }\end{array}$ & $\begin{array}{l}\text { Workfor } \\
\text { ce } \\
\text { - (Schuh et al. } \\
\text { 2015) } \\
\text { - (Faller and } \\
\text { Feldmúller } \\
2015 \text { ) } \\
\text { - (Weyer et } \\
\text { al. 2015) } \\
\text { - (Kemény et } \\
\text { al. 2016) } \\
\text { - Prinz et al. } \\
2016\end{array}$ & $\begin{array}{l}\text { Communication } \\
\text { - (Ray and Jones 2006) } \\
\text { - (Xun 2012) } \\
\text { - (Hao and Helo 2017) } \\
\text { - (Shariatzadeh et al. } \\
\text { 2016) } \\
\text { - (Lee et al. 2015) } \\
\text { - (Lee et al. 2014) } \\
\text { - (Thames and Schaefer } \\
2016 \text { ) } \\
\text { - (Thramboulidis and } \\
\text { Christoulakis 2016) } \\
\text { - (C. C. Lin et al. 2016) } \\
\text { - (Francalanza, Borg, and } \\
\text { Constantinescu 2017) } \\
\text { - (Ju Yeon et al. 2017) } \\
\text { - (C.-C. Lin et al. 2017) } \\
\text { - (Liu et al. 2017) } \\
\text { - (Tantik and Anderl 2017) } \\
\text { - (Wenas et al. 2017) } \\
\text { (Wan et al. 2017) }\end{array}$ & $\begin{array}{l}\text { Control } \\
\text { System } \\
\text { - (Quan and Li 2011) } \\
\text { - (Veza et al. 2015) } \\
\text { - (Zawadzki and } \\
\text { - Zywicki 2016) } \\
\text { - (Wang et al. 2015) } \\
\text { - (Wang et al. 2016) } \\
\text { - (Park 2016) } \\
\text { ( } \text { Eladdara and } \\
\text { - (Ivanovo 2015) } \\
\text { - (Xue et al. 2016) } \\
\text { - (Adamson et al. } \\
\text { 2017) } \\
\text { - (Chiu et al. 2017) } \\
\text { - (Y.-C. Lin et al. } \\
\text { 2017) } \\
\text { - (Meissner et al. } \\
\text { 2017) } \\
\text { - (Xu et al. 2017) } \\
\text { - (Hirmer et al. 2017) }\end{array}$ & $\begin{array}{l}\text { Digital twin } \\
\text { - Zhuang et al. } 2017 \\
\text { - Cai et al. } 2017 \\
\text { - Vachálek et al. } 2017 \\
\text { - Uhlemann et al. } \\
2017 \\
\text { - Tao and Zhang } 2017 \\
\text { - Schleich et al. 2017 } \\
\text { - Söderberg et al. } \\
2017 \\
\text { - Zhuang et al. 2018) } \\
\text { - Schluse et al. 2018) } \\
\text { - Qi an and Tao 2018 } \\
\text { - Haag and Anderl } \\
\text { 2018 } \\
\text { - Wagner et al. } 2018 \\
\text { - Mortensen et al } \\
\text { 2018 }\end{array}$ & $\begin{array}{l}\text { Predictive } \\
\text { maintenance } \\
\text { - Moyne et al. } 2013 \\
\text { - Lao et al. } 2014 \\
\text { - Zavoda at al. } 2014 \\
\text { - Sayed et al. } 2015 \\
\text { - Wang et al. } 2015 \\
\text { - Liu et al. } 2016 \\
\text { - Bai V et al. } 2016 \\
\text { - Italia \& Stefano } 2016 \\
\text { - Chiu et al. } 2017 \\
\text { - Tamer \& schlumberger } \\
2017 \\
\text { - Borgi et al. } 2017 \\
\text { - Civerchia et al. } 2017 \\
\text { - Aivaliotis et al. } 2017 \\
\text { - Yan et al. } 2017 \\
\text { - Zarte et al. } 2017 \\
\text { - Tsai \& Ko } 2017\end{array}$ \\
\hline
\end{tabular}

Figure 1. Classification of bibliographical references.

\section{Approaches in a Smart Factory}

This section, analysis the references in the eight categories, trying to give more insight about the suggested requirements and the existing works in each category. 


\subsection{Surveys}

This category includes works suggesting reviews, surveys, and tutorials about the smart factory systems or one of its enablers. References in this category investigate and analyze existing works that try to provide solutions towards the smart factory system. Table 2 contains an analysis of these references with respect to the requirements of a smart factory. As illustrated in Table 2, the requirements related to modular machine tools, standard infrastructure, standard communication and CPS, decentralized control architecture, and service orientations (R1, R6, R7, R12, and R20) attracted the most attention in the literature.

Table 2. Analysis of survey references with respect to the smart factory requirements.

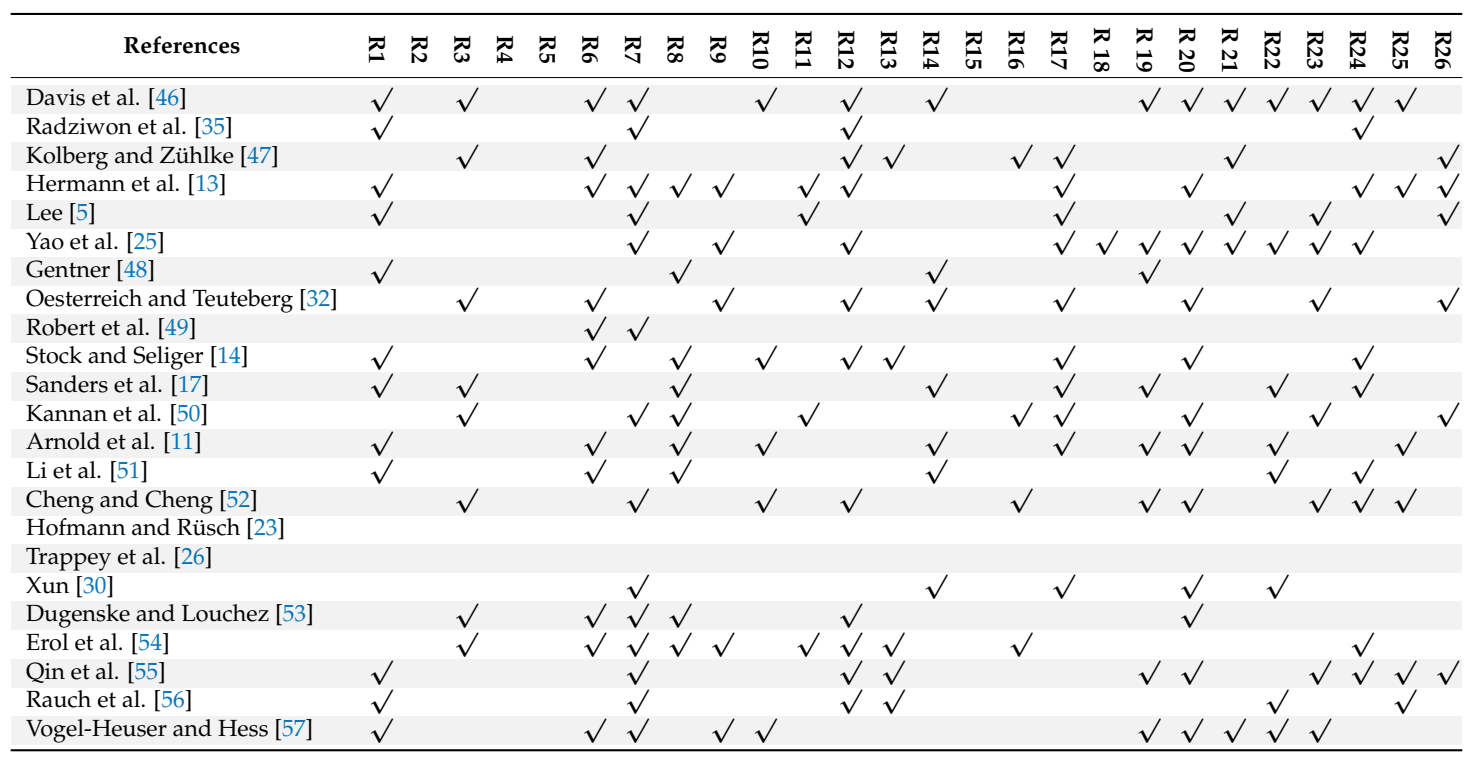

In contrast, requirements related to modular material handling, reconfigurable tools, sharing meaningful information, smart products, capturing the actual factory, standardizing the virtual modelling language and healability (R9, R13, R18 and R26) have attracted less attention. While R2, R4, R5, and R15 requirements have not been considered.

\subsection{Perspectives}

This category focuses on references that present their perspective in how the smart factory should be. They attempted to shape the future smart factory. The references in this category discusses arguments that justify the development of technical enablers, software structure and strategies to achieve the implementation of the smart factory. Such arguments guide researchers and manufacturers to contribute to shaping the future of the smart factory system. Table 3 analysis these references with respect to the suggested requirements. As we see from the table, requirements related to standard communication and CPS, modular and decentralized control architecture, and service orientation (R7, R12 and R20) gained most of the attention. In other hand, requirements related to modular material handling system, reconfigurable fixture, reconfigurable tools, capturing actual factory and standardized virtual modeling language (R2, R4, R5, R15, and R18) have not been considered. 
Table 3. Analysis of perspectives references with respect to the smart factory requirements.

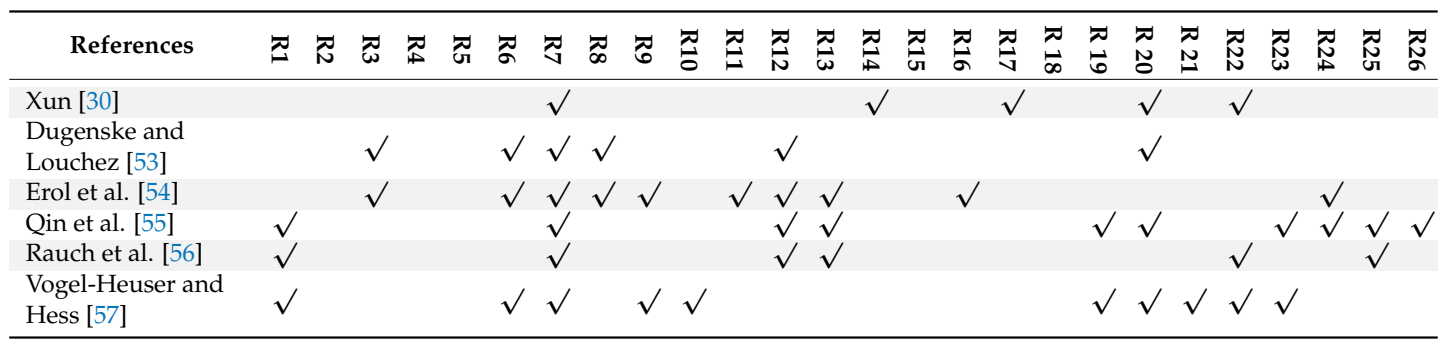

\subsection{System Design}

This category includes references that have system engineering concerns. References in this category provide mechanical, electrical, mechatronic, computer and control engineering solutions that enable the technical requirements of the smart factory. Requirements increase not only the flexibility and reconfigurability of systems but also the modularity of system components. Reconfigurability refers to the ability to change the shop floor layout and adjust process functions. The basic component of the smart factory is known as a module, which is an autonomous machine tool, workstation or material handling device that can perform a set of tasks. A module is loosely coupled and can be moved, added, or removed from the system in a plug-and-play manner [58]. Gorecky et al. [45] described a module as a puzzle block that can work alone or in combination with other modules to form a production system (Figure 2). Modular architecture requires both standards and modular supply infrastructure that can serve different types of modules that are supplied by different manufacturers.

A modular infrastructure can combine production modules in a production system with minimal configuration efforts. A standard and flexible infrastructure allows the connection of system components to all required supply layers. An example of such an infrastructure is the connector suggested by Han-Modular ${ }^{\circledR}$ technology [59] (Figure 3). This connector provides the connected production modules with compressed air, a three-phase current, the security concept, and an Ethernet-based communication via the "SF modular plug".

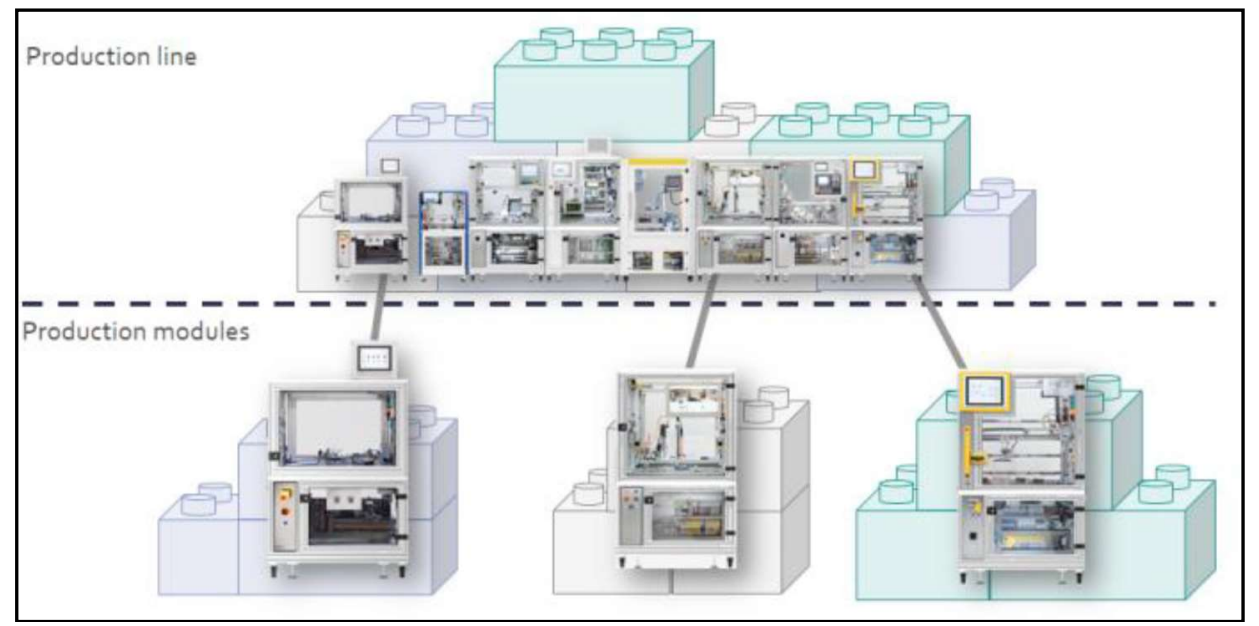

Figure 2. Smart factory modules [45] (ㄷ 2016 IFAC. Reproduced with permission from D. Gorecky, S. Weyer, A. Hennecke, D. Zühlke “Design and Instantiation of a Modular System Architecture for Smart Factories", IFAC-PapersOnline, 49, 31 (2016)). 


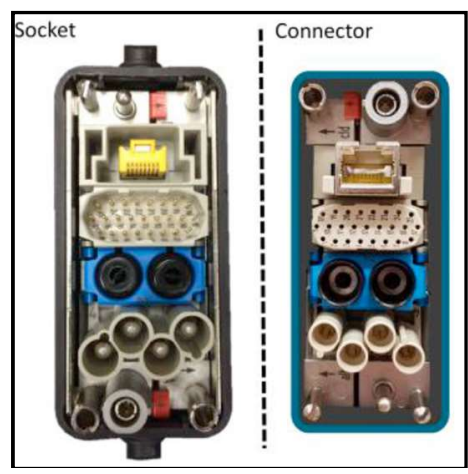

Figure 3. Modular module connector.

Modularity is not limited to the ability to change the layout of the shop floor. Smart factory modules also have a flexible structure that allows the extension of the module to increase production capacity or integrate new functionalities. Examples include expanding the functionality of a machine tool by adding an axis of motion and expanding a fixture by readjusting it to hold a new part. Expanded functionality enables both the production of more complex types of parts and the production of a variety of types of parts on the same machine. Studies in this category have attracted very little attention. Most of the studies presented were conducted in learning-factory projects such as Smart Factory KL [36], AAU Smart Production project [60,61]. Also, some works are deployed in a real environment. For example, Andersen et al. [62] designed a collaborative robotic manipulator with autonomous mobile platform for flexible part feeding processes. The deployments were carried out in a real industrial environment at FESTO CP Factory.

\subsection{Workforce}

This category focuses on works that discuss the role of human worker in the smart factory system. References in this category suggest tutorial or software tools that help worker to integrate in the system. In a traditional dedicated manufacturing line, the workforce has a specific and repetitive task, and high-level skill is not required. In a flexible manufacturing system, machines and robots replace the workforce where a high automation level would be appropriate. The smart factory system introduces a new concept of the role of the workforce in the production system. Workers should be highly skilled not only to cope up with renewable products and processes but also to have the supervision and problem-solving skills to autonomously address failures [63]. Smart factory workers integrate with the system, can access the product and process information, and have sufficient programming and mechatronics skills to fix software and technical problems. Most of the innovative ideas to improve the processes and products come from the worker, where s/he is the top expert on the system.

A learning factory is the best choice for obtaining the worker skills described above. In learning factories, workers have the opportunity to learn processes and related tasks and generate real-time data, which are used to evaluate the learning process and improve the process condition [64]. In addition, such factories help workers test their innovative ideas empirically. Such factories are presented in $[63,65,66]$. Another focus of the references in this category involves building hardware and software interfaces to assist the worker in performing tasks. In assembly stations, they suggested a hardware interface to visualize the entire CAD model of every single variant to be produced. During assembly, these interfaces guide workers to perform the tasks and provide all the construction information required, such as the necessary tools and parts. In addition, the process parameters are displayed, e.g., tightening torque for a screw [36,63]. Figure 4 shows an example of these interfaces. Another type of worker interface is augmented reality glasses, which are used to assist workers in the diagnostics and maintenance of failed parts. Such interfaces help workers understand the situation, suggest possible solutions and guide workers through the maintenance task [67]. 


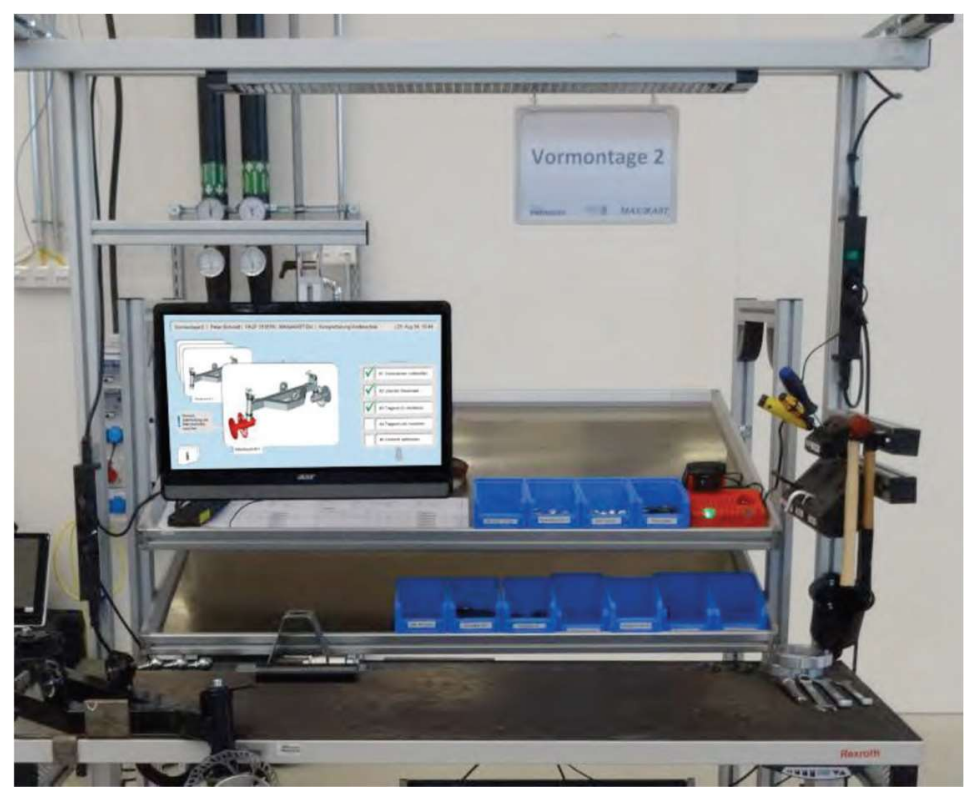

Figure 4. Manual assembly station equipped with a touchscreen [63] (Reproduced with permission from Elsevier).

\subsection{Communication}

The reviewed research that related to communication concerns is focused on suggesting solutions to enable data exchange between the internal elements of the system and CM. The field of CPS has attracted most of the attention in these categories. They aim at building systems that can integrate computation, networking, and physical processes. Such systems do not yet exist, but the suggested approaches represent paths to such system. Examples of such paths can be found in $[33,44,68]$.

The standardized communication protocol of sharing information is a crucial enabler of communication [69]. A standard protocol should be used by manufacturers, cloud system providers, customers, software suppliers, etc. Interoperability cannot be achieved in a smart factory without such standardization. Ray and Jones [70] discussed interoperability issues related to current standards and describe two projects leading towards interoperability standards. Wan et al. [71] suggested an interoperability platform for cloud computing, mobile computing and existing control technology. Chun Cheng et al. [72] suggested installing wireless sensors in factories to collect information continuously. They suggested a scheduling approach to deploy in-group sensors aimed at reducing energy consumption.

Semantic technology has the potential to resolve the issue of standardized communication $[6,25,73]$. Semantic technology represents information (data and knowledge) in a form that is understandable by both machines and human agents. Another important issue in communication is secure access to information. Because both services and information will offered in $\mathrm{CM}$, access to information should be secure [74]. For example, design and manufacturing information should not accessible to competitors.

\subsection{Control Systems}

This category includes references focus on the following issues:

- Control architecture: The authors developed control architecture to monitor and control a smart factory. These works primarily focus on decentralized and multi-agent systems. In this type of architecture, the individual elements must have the ability to process information and to make and execute decisions, thereby becoming autonomous. One interesting discussion and comparison of centralized, decentralized and hybrid control architecture in I4.0 was presented in [75]. They noted 
the strengths and weaknesses of each type of architecture leading to I4.0. There have also been attempts to suggest a control architecture for a smart factory. Hirmer et al. [76] suggested an online monitoring and control system that can react to situations. Adamson et al. and Wang et al. [4,77] suggested control architecture aimed at integrating industrial wireless network, cloud, and physical system components. Wang et al. [78] suggested a multi-agent decentralized control architecture focused on preventing the occurrence of deadlock.

- CPS and cloud-computing-based control architecture: The authors developed control architecture along with CPS or cloud-computing platforms to control and monitor the system. Adamson et al. [4] suggested adaptive decentralized control architecture in CPS and an outline-of-information framework to support this approach. Chiu et al. [79] focused on applying CPS and cloud computing to an intelligent predictive maintenance system. Yu-Chuan et al. [80] focused on enhancing the yield of semiconductor products and developed a smart manufacturing platform.

- Standardization in control architecture and industrial automation technologies: Researchers realized the need to standardize control architecture and protocol to monitor and control the smart factory system, specifically with multi-vendor equipment. Park [12] noted the need to standardize the control of the industrial broad-band infrastructure and to effectively integrate the company's internal and external value chains. Haddara and Elragal [69] highlighted the fact that ERP requires a standard protocol for machine-to-machine communication and standard communication to communicate with vendors. Researchers have also discussed existing automation technologies that enable control of such a system. Quan and Li [81] introduced characteristics of soft PLCs and described their architecture as a potential standard and control enabler for SF control architecture.

- System management approaches: Some authors have suggested approaches to support and facilitate control system tasks. Xu et al. [82] developed a visual analytical system for assembly lines. This system provides real-time tracking and an analysis of historical performance. Zawadzki and Zywicki [42] suggested a new method of designing a product in smart factories that combines virtual reality and rapid prototyping. Veza et al. [83] suggested an MCDM approach to manage the virtual production network in the selection of production partners.He et al. [84] suggested an algorithm to manage the storage space of flash memory aimed at optimizing the performance of cloud computing. Ivanov et al. [85] suggested a dynamic model and algorithm for the simultaneous selection of machine structure and job assignment.Xue et al. [86] suggested a computational experiment-based evaluation approach to match service providers (service strategy) with customer demands.

\subsection{Digital Twin}

Works in this category focus on developing a DT to pave a way for the integration of cyber and physical world. In DT, a virtual model of physical objects are created in a digital world to simulate and monitor their behavior in real environments $[87,88]$. The DT consists of three components, which are the physical entities, the virtual models, and the connected data that tie between them [89]. The application of DT in manufacturing are directed to the following:

- Designing and verifying of products: Some authors have developed a DT framework to support product design. Such framework enables the iterative optimization of design scheme to guide designers to adjust their expectation and improve the design model. In this manner, Schleich et al. [90] suggested a skin model, which is an abstract model of the physical interface between a workpiece and its environment. Mortensen et al. [91] suggested a framework for virtual commissioning for reconfigurable manufacturing system. The framework is based on classifying different elementary configuration in a matrix to identify virtual recommission tasks. They conducted the framework exploration on a lab demonstrator. 
- Monitoring product over production life-cycle: Some authors view DT as a comprehensive digital representation of product from the early design stage to the end of product life-cycle. Haag and Anderl [92] proposed such digital DT representing of an individual product including properties, condition, and behavior of the real-life object. To prove this concept, they developed test bench and demonstrated it in bending beam process at their laboratory. Söderberg et al. [90] suggested a DT for geometry assurance used in design face to develop robust products and to distribute tolerances, and in the production phase to serve as a real-time controller for the assembly system.

- Designing and verifying of processes and production lines: Some authors have developed a DT to assist the design of process function and production line capabilities. This DT provides engineering analysis capabilities and supports decision-making over the system design and solution evaluation. Zhuang et al. [93] suggested a DT to design a hollow glass production line.

- Managing and optimizing manufacturing process: Some authors have developed a DT to monitor and control manufacturing processes from the input of raw material to the output of finished product. Such systems trace the process performance, analysis real data, and simulate potential improvement [94]. Tao and Zhang [92] proposed a DT framework for production assembly shop-floor. In Zhuang et al. [95] they implemented the suggested framework in a satellite assembly environment. Vachálek et al. [96] suggested a DT framework of a production line and applied it in a laboratory environment. Schluse et al. [97] moved a step toward application of virtual twin. They experimented the suggested framework in a reconfigurable assembly cell using simulation on a virtual testbed. Uhlemann et al. [98] showed how the DT concept can realize the $\mathrm{CP}$ production system in small and medium enterprises.

- Enhancing resources overhaul maintenance: Some authors have developed DT to trace resources digital behavior to diagnose and prognosticate faults, failure, and performance deviation. Once such problems are detected, the suitable action will be simulated in virtual model to evaluate the effectiveness of the correction action to avoid sudden downtime. In this context, Cai et al. [99] developed a virtual machine tool throughout the integration of manufacturing data and sensor data. They demonstrated the suggested framework in 3-axis vertical milling machine.

\subsection{Predictive Maintenance}

Predictive maintenance reduces maintenance frequency to lowest possible state leading to a huge cost saving in keeping resources in normal working condition [100]. Also, catastrophic situations can be avoided, where anomalies are detected a priori, and required maintenance is undertaken on time to prevent failure occurrence. Sometimes small failure can lead to massive failure and shutdown. Manufacturing resources are similar to a chain fashion; failure of one ring may cause a downtime for the whole chain. In SF system, big data are collected about the resources, and products, and analyzed in real time to forecast equipment status and information. Patterns can be drawn and a suitable maintenance strategy can be tested and evaluated [101]. Existing works in predictive maintenance can be classified to the following:

- Reviews: Some authors discussed the benefits of predictive maintenance in some environments or the potential of some tools to enable predictive maintenance. Temer and Schlumberger and Italia and Stefano [102,103] discussed the opportunities of using IoT, data analytics, and machine learning approaches in oil and gas industry. They highlighted the importance of predictive maintenance for downhole and valves, respectively. Zavoda et al. [104] discussed the benefits of using standardized and modular controller for implementing just in time maintenance.

- Simulation-based approaches: Some authors suggested approaches to simulate the behavior of the system or its equipment(s) to determine the time between failure or the loss of efficiency. Zatre et al. [105] Suggested a simulation model to evaluate failures in a predefined process plans. They used AnyLogic simulation software to implement the model in an industrial case study. 
Aivaliotis et al. [106] developed a control system to predict the remaining time that the resources perform its intended function. The model simulate data from machine controller and external sensors to schedule maintenance activities.

- Condition-based approaches: Some authors used actual operating condition of equipment and system to optimize overall resource utilization. Borgi et al. [106] analyzed electrical data to diagnose and prognosticate industrial robot. Tsai and Ko [107] analyzed time-frequency signal of servo motors embedded in industrial robot. Bai V [108] used smart sensors and data analytics to monitor the manufacturing plant. Lao and Ellis [109] suggested a maintenance model by integrating scheduled preventive control actuator maintenance, process economics, and process control. The model optimizes economic process performance over a (control) horizon by using a dynamic process model to predict the evolution of the process.

- Condition-based approaches enhanced by artificial intelligent tool: Some authors developed artificial algorithms to use a continuous acquired data to provide a detail insight about the status of the equipment and trigger action if the failure of pattern is detected. The effectiveness of such approaches is measured by the ability to forecast the correct patterns and provide sufficient warning time. Yuanyuan et al. [110] suggested a general regression neural network model for equipment maintenance. They experimented the model using dump truck, wheel loader, numerical control machine, and metal cutting machine. Wang et al. [100] suggested an artificial neural network model for the maintenance activities of machine tools. Sayed et al. [111] suggested a framework based on inferencing probability of the occurrence of an unobservable fault hypothesis based on the measured (observed) evidence. Yan et al. [101] suggested a framework for structuring and characterizing multisource industrial big data using semantic web technology. The framework enhanced by enveloped analysis and fusion method to identify data patterns. They implemented the suggested framework in an industrial case study. Civerchia et al. [112] designed and deployed Industrial IoT system architecture for electricity power plant. Chiu et al. [79] developed CP agent system and MC to support the predictive maintenance of wide range of factory equipment. Moyne et al. [36] developed a monitoring dashboard for equipment predictive maintenance in two sites.

\section{Discussion}

In this section, we present the result of the suggested literature survey and discuss some research challenges of the smart factory system, which are worth investigating.

- Focus of existing research: Most of the references analyzed in this review focused on three categories (Figure 1): surveys, communication, and control systems. Few research papers focused on system design and the technical enabling of a smart factory system. Although some technical works and technologies exist in the industry, researchers placed little emphasis on presenting the current state of industry or developing new technologies. Indeed, such research requires many resources and has great potential for realization of the smart factory.

- Requirements of a smart factory: Discussion on this point is related to the perspectives and survey category, which includes more than one requirement. The other categories are dedicated to one or two requirements. In general, aside from the six requirements set forth in [45], the requirements of the smart factors are neither illustrated nor clearly mentioned in any of the references. It is noticed that requirements related to modular material handling equipment (R2), reconfigurable fixtures (R4), reconfigurable tools (R5), and capturing the actual factory (R15) are not mentioned in any paper.

- Interoperability: One of the biggest challenges is that the smart factory system will have to achieve a high level of sharing and interchanging information between their products, the infrastructure of their production and processes and their control system and real-time application [15]. Such data are numerous, and the complexity of their interoperability is increased 
when various management levels, suppliers and consumers use them. Security and authentication also represent substantial challenges to interoperability.

- Control architecture: Research in this field focuses on decentralized control architecture. Such architecture is fitted to a dynamic environment and quickly adapts to change. Despite these benefits, decentralized control architecture is challenged by the effort required to coordinate single modules, each attempting to pursue its own objective and potentially disrupting the global objective of the system [75]. Hybrid architectures (a mixture of centralized and decentralized architectures) have good properties with respect to such issues and have manifold possibilities for applications. These types of architectures are highlighted in [113].

- Vagueness of digitization and CPS: Many works attempted to clarify the looseness and vagueness of the term "CPS". Until now, there has been no clear view of CPS and how it can enable the management, interoperability, and control of data inside the smart factory system and among the various factories with heterogeneous technology suppliers and various customers, each of which have different cultures and knowledge experience. Realization of CPS is one of the most challenging aspects of a smart factory system.

- Manufacturing cloud computing: As previously mentioned in this paper, big data opened the door to substantial potential, and CM promised to offer new possibilities for smart factory systems. However, it is not enough merely to have big data. Rather, the ability to access and analyze these data is also necessary. Therefore, one important challenge involves creating a powerful tool that analyses big data and deploys it in CM to offer better manufacturing services.

- Learning factories: Learning factories help realize new technologies and empirically apply new ideas that lead to the smart factory. Learning factories are the best environment for training the workforce in their future roles, integrating them into such an environment and stimulating new ideas and inventions. Germany realized these benefits and established many learning factories, such as Smart Factory KL [36] and The Learning Factory at the Campus Velbert/Heiligenhaus [64]. Such factories are worth establishing.

- Gaps between the smart factory and existing manufacturing systems: Qin et al. [56] analyzed the gaps between existing manufacturing systems, including single-station automated cells, automated assembly, flexible manufacturing, computer-integrated manufacturing and reconfigurable manufacturing systems. The reconfigurable manufacturing system is the most closer to a smart factory system, followed by the flexible manufacturing system. The reconfigurable manufacturing system is superior in real-time capability and customization. Automated assembly systems and computer-integrated systems are quite far from smart factory systems. These systems have rigid and highly automated components. Indeed, there is a long way to go to reach the smart factory system.

- Maturity of the smart factory system: The smart factory system could be very helpful for small and medium-size enterprises to increase their competitiveness and productivity [35]. The smart factory is in the emerging phase and as with any such system, it is confronted by reluctance-or at least neglect-from many manufacturing companies [114]. This reluctance is attributable to a lack of awareness of the benefits of transforming into a smart factory system, especially for small and medium-size enterprises. Therefore, it would be worthwhile not only to increase awareness and highlight the benefits of a smart factory system but also to present case studies.

\section{Conclusions}

In this paper, we focus on new trends in the manufacturing field, particularly the vision of I4.0, which will revolutionize manufacturing systems. We focused on smart factory systems and investigated existing work that is leading towards such a system. The smart factory system is still only a vision, and there is no clear view of the requirements, the elements and the features of those elements that will help to realize this system. This conclusion motivated us to attempt to itemize the requirements of 
the smart factory system, investigate these requirements against the design principles, and review and classify the related literature on smart factory systems.

The analysis presented in this paper resulted in several valuable conclusions. Most of the existing approaches use their perspective and opinion to shape a vision of future manufacturing. Most of these approaches placed greater emphasis on a general vision of I4.0, but few of them focused on the smart factory. They explained a general overview of design principles but did not describe the elements and their features in a smart factory system. Control systems and communication attracted some attention. Researchers explained the architectures and behaviors in such systems, and suggested case studies to realize and deploy these ideas, but there is still a need for more applications to realize these ideas in industry. In addition, existing work placed very little emphasis on the technical enablers and physical components needed for a smart factory system. Finally, we discussed the most important issues derived from this paper and suggested several directions for future research.

Author Contributions: This review paper was principally developed and written by the first author (M.M.M.). The supervision carried out by the second author (A.M.A.-A.). The third and fourth authors (B.S. \& H.A.) suggested some improvement to the paper.

Funding: The authors are grateful to the Raytheon Chair for Systems Engineering for funding.

Acknowledgments: The authors would like to thank @ 2016 IFAC and Gorecky et al. 2016 [45] for the permission granted to reproduce Figure 2.

Conflicts of Interest: The authors declare no conflicts of interest.

\section{References}

1. Gaub, H. Customization of mass-produced parts by combining injection molding and additive manufacturing with Industry 4.0 technologies. Reinf. Plast. 2016, 60, 401-404. [CrossRef]

2. Schumacher, A.; Erol, S.; Sihn, W. A Maturity Model for Assessing Industry 4.0 Readiness and Maturity of Manufacturing Enterprises. Procedia CIRP 2016, 52, 161-166. [CrossRef]

3. Quik, A. Examination of the Moderating Effect of Country Cultura 1 Dimensions on the Relation between Board Gender Diversity and Firm Financial Performance. Master's Thesis, Radboud University, Nijmegen, The Netherlands, 2016.

4. Adamson, G.; Wang, L.; Moore, P. Feature-based control and information framework for adaptive and distributed manufacturing in cyber physical systems. J. Manuf. Syst. 2017, 43, 305-315. [CrossRef]

5. Lee, J. Smart Factory Systems. Informatik Spektrum 2015, 38, 230-235. [CrossRef]

6. Liu, X.F.; Shahriar, M.R.; Al Sunny, S.M.N.; Leu, M.C.; Hu, L. Cyber-physical manufacturing cloud: Architecture, virtualization, communication, and testbed. J. Manuf. Syst. 2017, 43, 352-364. [CrossRef]

7. Lu, Y. Industry 4.0: A survey on technologies, applications and open research issues. J. Ind. Inf. Integr. 2017, 6,1-10. [CrossRef]

8. Mowery, D.C.; Rosenberg, N. Technology and the Pursuit of Economic Growth; Cambridge University Press: New York, NY, USA, 1989.

9. Chien, C.-F.; Hong, T.-Y.; Guo, H.-Z. An empirical study for smart production for TFT-LCD to empower Industry 3.5. J. Chin. Inst. Eng. 2017, 40, 552-561. [CrossRef]

10. Koch, V.; Kuge, S.; Geissbauer, D.R.; Schrauf, S. Oppertunities and Challanges of the Industrial Internet. 2015. Available online: http:/ / www.strategyand.pwc.com/reports/industry-4-0 (accessed on 23 January 2015).

11. Arnold, C.; Kiel, D.; Voigt, K. Innovative Business Models for the Industrial Internet of Things. BHM 2017, 162, 371-381. [CrossRef]

12. Park, S. Development of Innovative Strategies for the Korean Manufacturing Industry by Use of the Connected Smart Factory (CSF). Procedia Comput. Sci. 2016, 91, 744-750. [CrossRef]

13. Hermann, M.; Pentek, T.; Otto, B. Design Principles for Industrie 4.0 Scenarios: A Literature Review. Working Pap. 2015. [CrossRef]

14. Stock, T.; Seliger, G. Opportunities of Sustainable Manufacturing in Industry 4.0. Procedia CIRP 2016, 40, 536-541. [CrossRef]

15. Alexandre, M. Industrie 4.0 Framework, Challenges and Perspectives. Ph.D. Thesis, RheinMain University, Wiesbaden, Germany, 2014. 
16. Nieuwenhuize, G. Smart Manufacturing for Dutch SMEs: Why and How? Master's Thesis, Erasmus University, Rotterdam, The Netherlands, 2016.

17. Sanders, A.; Elangeswaran, C.; Wulfsberg, J. Industry 4.0 Implies Lean Manufacturing: Research Activities in Industry 4.0 Function as Enablers for Lean Manufacturing. J. Ind. Eng. Manag. 2016, 9, 811-833. [CrossRef]

18. Wolter, M.I.; Mönnig, A.; Hummel, M.; Schneemann, C.; Weber, E.; Zika, G.; Helmrich, R.; Maier, T.; Neuber-Pohl, C. Industry 4.0 and the Consequences for Labor Market and Economy: Scenario Calculations within the Scope of the BIBB-IAB Qualification and Occupational Field Projections. Available online: https:/ /ideas.repec.org/p/iab/iabfob/201508_en.html (accessed on 2 August 2015). (In Germany)

19. Akeson, L. Industry 4.0: Cyber-Physical Systems and Their Impact on Business Models. Master's Thesis, Karlstads University, Karlstad, Sweden, 2016.

20. Brettel, M.; Friederichsen, N.; Keller, M.; Rosenberg, M. How virtualization, decentralization and network building change the manufacturing landscape: An industry 4.0 perspective. Int. J. Mech. Ind. Sci. Eng. 2014, 8, 37-44.

21. Baums, A. How to Navigate Digitization of the Manufacturing Sector. Available online: https://www. mckinsey.de/files/mck_industry_40_report.pdf (accessed on 2 May 2015).

22. Balasingham, K. Industry 4.0: Securing the Future for German Manufacturing Companies. Master's Thesis, University of Twente, Enschede, The Netherlands, 2016.

23. Hofmann, E.; Rüsch, M. Industry 4.0 and the current status as well as future prospects on logistics. Comput. Ind. 2017, 89, 23-34. [CrossRef]

24. The Federal Ministry of Education and Research. 2017. Available online: http://www.plattformi40.de/I40/Navigation/EN/Industrie40/WhatIsIndustrie40/what-is-industrie40.html;jsessionid= 1DC8D8017337F5A6153A146236669ABA (accessed on 2 May 2018).

25. Yao, X.; Jin, H.; Zhang, J. Towards a wisdom manufacturing vision. Int. J. Comput. Integr. Manuf. 2015, 28, 1291-1312. [CrossRef]

26. Trappey, A.J.C.; Trappey, C.V.; Fan, C.Y.; Hsu, A.P.T.; Li, X.K.; Lee, I.J.Y. IoT patent roadmap for smart logistic service provision in the context of Industry 4.0. J. Chin. Inst. Eng. 2017, 40, 593-602. [CrossRef]

27. Khan, M.; Wu, X.; Xu, X.; Dou, W. Big data challenges and opportunities in the hype of Industry 4.0. In Proceedings of the IEEE International Conference on Communications (ICC), Paris, France, 21-25 May 2017; pp. 1-6.

28. Loechner, J. 90\% of Today's Data Created In Two Years. Available online: https://www.mediapost.com/ publications/article/291358/90-of-todays-data-created-in-two-years.html (accessed on 22 December 2016).

29. Gokalp, M.O.; Kayabay, K.; Akyol, M.A.; Eren, P.E.; Kocyigit, A. Big Data for Industry 4.0: A Conceptual Framework. In Proceedings of the International Conference on Computational Science \& Computational Intelligence (CSCI), Las Vegas, NV, USA, 15-17 December 2016; pp. 431-434.

30. Xun, X. From cloud computing to cloud manufacturing. Robot. Comput. Integr. Manuf. 2012, $28,75-86$.

31. Buxmann, P.; Hess, T.; Ruggaber, R. Internet of Services. Bus. Inf. Syst. Eng. 2009, 1, 341-342. [CrossRef]

32. Oesterreich, T.D.; Teuteberg, F. Understanding the implications of digitisation and automation in the context of Industry 4.0: A triangulation approach and elements of a research agenda for the construction industry. Comput. Ind. 2016, 83, 121-139. [CrossRef]

33. Lee, J.; Bagheri, B.; Kao, H.A. A Cyber-Physical Systems architecture for Industry 4.0-based manufacturing systems. Manuf. Lett. 2015, 3, 18-23. [CrossRef]

34. Pîrvu, B.-C. Research Regarding the Digital Factory Modelling and Implementation Into Real Manufacturing Systems. Ph.D. Thesis, University of Sibiu, Sibiu, Romania, 2011.

35. Radziwon, A.; Bilberg, A.; Bogers, M.; Skov, E. The Smart Factory: Exploring Adaptive and Flexible Manufacturing Solutions. Procedia Eng. 2014, 69, 1184-1190. [CrossRef]

36. Weyer, S.; Schmitt, M.; Ohmer, M.; Gorecky, D. Standardization as as the the crucial crucial challenge challenge Towards Standardization as the crucial challenge for highly production systems for highly modular, multi-vendor production systems for highly modular, multi-vendor productio. IFAC-PapersOnLine 2015, 48, 579-584. [CrossRef]

37. Tantik, E.; Anderl, R. Integrated Data Model and Structure for the Asset Administration Shell in Industrie 4.0. Procedia CIRP 2017, 60, 86-91. [CrossRef]

38. Shariatzadeh, N.; Lundholm, T.; Lindberg, L.; Sivard, G. Integration of Digital Factory with Smart Factory Based on Internet of Things. Procedia CIRP 2016, 50, 512-517. [CrossRef] 
39. SoftPLC. Smart SoftPLC's Controllers. 2017. Available online: http://softplc.com/products/controllers / smart/ (accessed on 2 May 2018).

40. Shamim, S.; Cang, S.; Yu, H.; Li, Y. Examining the feasibilities of Industry 4.0 for the hospitality sector with the lens of management practice. Energies 2017, 10, 499. [CrossRef]

41. Montanus, M. Business Models for Industry 4.0. Master's Thesis, Faculty of Technology, Policy and Management, Delft University of Technology, Delft, The Netherlands, 2016.

42. Zawadzki, P.; Zywicki, K. Smart product design and production control for effective mass customization in the industry 4.0 concept. Manag. Prod. Eng. Rev. 2016, 7, 105-112. [CrossRef]

43. Fischer, T.; Gebauer, H.; Fleisch, E. Service Business Development; Cambridge University Press: Cambridge, UK, 2012.

44. Penas, O.; Plateaux, R.; Patalano, S.; Hammadi, M. Multi-scale approach from mechatronic to Cyber-Physical Systems for the design of manufacturing systems. Comput. Ind. 2017, 86, 52-69. [CrossRef]

45. Gorecky, D.; Weyer, S.; Hennecke, A.; Zühlke, D. Design and Instantiation of a Modular System Architecture for Smart Factories. IFAC-PapersOnLine 2016, 49, 79-84. [CrossRef]

46. Davis, J.; Edgar, T.; Porter, J.; Bernaden, J.; Sarli, M. Smart manufacturing, manufacturing intelligence and demand-dynamic performance. Comput. Chem. Eng. 2012, 47, 145-156. [CrossRef]

47. Kolberg, D.; Zühlke, D. Lean Automation enabled by Industry 4.0 Technologies. IFAC-PapersOnLine 2015, 28, 1870-1875. [CrossRef]

48. Gentner, S. Industry 4.0: Reality, Future or just Science Fiction? How to Convince Today's Management to Invest in Tomorrow's Future! Successful Strategies for Industry 4.0 and Manufacturing IT. CHIMIA Int. J. Chem. 2016, 70, 628-633. [CrossRef] [PubMed]

49. Robert, H.; Daniel, V.; Bilal, A. Engineering the Smart Factory. Chin. J. Mech. Eng. 2016, 29, $1046-1051$.

50. Kannan, S.M.; Suri, K.; Cadavid, J.; Barosan, I.; Van Den Brand, M.; Alferez, M.; Gerard, S. Towards industry 4.0: Gap analysis between current automotive MES and industry standards using model-based requirement engineering. In Proceedings of the IEEE International Conference on Software Architecture Workshops (ICSAW), Gothenburg, Sweden, 5-7 April 2017; pp. 29-35.

51. Li, X.; Li, D.; Wan, J.; Vasilakos, A.V.; Lai, C.F.; Wang, S. A review of industrial wireless networks in the context of Industry 4.0. Wirel. Netw. 2017, 23, 23-41. [CrossRef]

52. Cheng, S.Q.K.; Cheng, K. Future Digital Design and Manufacturing: Embracing Industry 4.0 and Beyond. Chin. J. Mech. Eng. 2017, 30, 1047-1049.

53. Dugenske, A.; Louchez, A. The Factory of The Future Will Be Shaped by The Internet of Things. Advant. Bus. Media 2014, 19, 1-5.

54. Erol, S.; Jäger, A.; Hold, P.; Ott, K.; Sihn, W. Tangible Industry 4.0: A Scenario-Based Approach to Learning for the Future of Production. Procedia CIRP 2016, 54, 13-18. [CrossRef]

55. Qin, J.; Liu, Y.; Grosvenor, R. A Categorical Framework of Manufacturing for Industry 4.0 and beyond. Procedia CIRP 2016, 52, 173-178. [CrossRef]

56. Rauch, E.; Dallasega, P.; Matt, D.T. The Way from Lean Product Development (LPD) to Smart Product Development (SPD). Procedia CIRP 2016, 50, 26-31. [CrossRef]

57. Vogel-Heuser, B.; Hess, D. Guest Editorial Industry 4.0 Prerequisites and Visions. IEEE Trans. Autom. Sci. Eng. 2016, 13, 411-413. [CrossRef]

58. Mabkhot, M.M.; Al-Samhan, A.; Darmoul, S. An information model to support reconfiguration of manufacturing systems. IFAC-PapersOnLine 2016, 49, 37-42. [CrossRef]

59. Han-Modular®Technology. Available online: https://www.harting.com/DE/en-gb/solutions/hanmodular (accessed on 2 May 2018).

60. Madsen, O.; Møller, C. The AAU Smart Production Laboratory for Teaching and Research in Emerging Digital Manufacturing Technologies. Procedia Manuf. 2017, 9, 106-112. [CrossRef]

61. Nardello, M.; Madsen, O.; Møller, C. The smart production laboratory: A learning factory for industry 4.0 concepts. CEUR Workshop Proc. 2017, 1898, 1-5.

62. Andersen, R.E.; Hansen, E.B.; Cerny, D.; Madsen, S.; Pulendralingam, B.; Bøgh, S.; Chrysostomou, D. Integration of a Skill-based Collaborative Mobile Robot in a Smart Cyber-physical Environment. Procedia Manuf. 2017, 11, 114-123. [CrossRef]

63. Schuh, G.; Gartzen, T.; Rodenhauser, T.; Marks, A. Promoting work-based learning through industry 4.0. Procedia CIRP 2015, 32, 82-87. [CrossRef] 
64. Prinz, C.; Morlock, F.; Freith, S.; Kreggenfeld, N.; Kreimeier, D.; Kuhlenkötter, B. Learning Factory Modules for Smart Factories in Industrie 4.0. Procedia CIRP 2016, 54, 113-118. [CrossRef]

65. Faller, C.; Feldmúller, D. Industry 4.0 learning factory for regional SMEs. Procedia CIRP 2015, 32, 88-91. [CrossRef]

66. Kemény, Z.; Beregi, R.J.; Erdos, G.; Nacsa, J. The MTA SZTAKI Smart Factory: Platform for Research and Project-oriented Skill Development in Higher Education. Procedia CIRP 2016, 54, 53-58. [CrossRef]

67. SmartFactoryKL. Manufacturer-Independent Industrie 4.0 Production Line. Available online: http: / / dfki3036.dfki.de/EN/industrie40_e.php (accessed on 22 December 2017).

68. Francalanza, E.; Borg, J.; Constantinescu, C. A knowledge-based tool for designing cyber physical production systems. Comput. Ind. 2017, 84, 39-58. [CrossRef]

69. Haddara, M.; Elragal, A. The Readiness of ERP Systems for the Factory of the Future. Procedia Comput. Sci. 2015, 64, 721-728. [CrossRef]

70. Ray, S.R.; Jones, A.T. Manufacturing interoperability. J. Intell. Manuf. 2006, 17, 681-688. [CrossRef]

71. Wan, J.; Yi, M.; Li, D.I.; Zhang, C.; Wang, S.; Zhou, K. Mobile Services for Customization Manufacturing Systems: An Example of Industry 4.0. IEEE Access 2016, 4, 8977-8986. [CrossRef]

72. Lin, C.C.; Deng, D.J.; Chen, Z.Y; Chen, K.C. Key design of driving industry 4.0: Joint energy-efficient deployment and scheduling in group-based industrial wireless sensor networks. IEEE Commun. Mag. 2016, 54, 46-52. [CrossRef]

73. Turner, C.J.; Hutabarat, W.; Oyekan, J.; Tiwari, A. Discrete Event Simulation and Virtual Reality Use in Industry: New Opportunities and Future Trends. IEEE Trans. Hum.-Mach. Syst. 2016, 46, 882-894. [CrossRef]

74. Zezulka, F.; Marcon, P.; Vesely, I.; Sajdl, O. Industry 4.0-An Introduction in the phenomenon. IFAC-PapersOnLine 2016, 49, 8-12. [CrossRef]

75. Meissner, H.; Ilsen, R.; Aurich, J.C. Analysis of Control Architectures in the Context of Industry 4.0. Procedia CIRP 2017, 62, 165-169. [CrossRef]

76. Hirmer, P.; Wieland, M.; Schwarz, H.; Mitschang, B.; Breitenbücher, U.; Sáez, S.G.; Leymann, F. Situation recognition and handling based on executing situation templates and situation-aware workflows. Computing 2017, 99, 163-181. [CrossRef]

77. Wang, S.; Wan, J.; Li, D.; Zhang, C. Implementing Smart Factory of Industrie 4.0: An Outlook. Int. J. Distrib. Sens. Netw. 2016, 12, 3159805. [CrossRef]

78. Wang, S.; Wan, J.; Zhang, D.; Li, D.; Zhang, C. Towards smart factory for Industry 4.0: A self-organized multi-agent system with big data based feedback and coordination. Comput. Netw. 2015, 101, 158-168. [CrossRef]

79. Chiu, Y.C.; Cheng, F.T.; Huang, H.C. Developing a factory-wide intelligent predictive maintenance system based on Industry 4.0. J. Chin. Inst. Eng./Chung-kuo K. Ch'eng Hsuch K'an 2017, 40, 562-571. [CrossRef]

80. Lin, Y.-C.; Hung, M.H.; Huang, H.C.; Chen, C.C.; Yang, H.C.; Hsieh, Y.S.; Cheng, F.T. Development of Advanced Manufacturing Cloud of Things (AMCoT)—A Smart Manufacturing Platform. IEEE Robot. Autom. Lett. 2017, 2, 1809-1816. [CrossRef]

81. Quan, L.; Li, L. The study of soft PLC running system. Procedia Eng. 2011, 15, 1234-1238.

82. Xu, P.; Mei, H.; Ren, L.; Chen, W. ViDX: Visual Diagnostics of Assembly Line Performance in Smart Factories. IEEE Trans. Vis. Comput. Graph. 2017, 23, 291-300. [CrossRef] [PubMed]

83. Veza, I.; Mladineo, M.; Gjeldum, N. Managing innovative production network of smart factories. IFAC-PapersOnLine 2015, 28, 555-560. [CrossRef]

84. He, J.; Jia, G.; Han, G.; Wang, H.; Yang, X. Locality-Aware Replacement Algorithm in Flash Memory to Optimize Cloud Computing for Smart Factory of Industry 4.0. IEEE Access 2017, 5, 16252-16262. [CrossRef]

85. Ivanov, D.; Dolgui, A.; Sokolov, B.; Werner, F.; Ivanova, M. A dynamic model and an algorithm for short-term supply chain scheduling in the smart factory industry 4.0. Int. J. Prod. Res. 2016, 54, 386-402. [CrossRef]

86. Xue, X.; Kou, Y.-M.; Wang, S.; Liu, Z.-Z. Computational experiment research on the equalization-oriented service strategy in collaborative manufacturing. IEEE Trans. Serv. Comput. 2016, 11, 369-383. [CrossRef]

87. Qi, Q.; Tao, F. Digital Twin and Big Data Towards Smart Manufacturing and Industry 4.0: 360 Degree Comparison. IEEE Access 2018, 6, 3585-3593. [CrossRef]

88. Söderberg, R.; Wärmefjord, K.; Carlson, J.S.; Lindkvist, L. Toward a Digital Twin for real-time geometry assurance in individualized production. CIRP Ann. Manuf. Technol. 2017, 66, 137-140. [CrossRef] 
89. Grieves, M. Digital Twin: Manufacturing Excellence through Virtual Factory Replication. Available online: https:/ / research.fit.edu/media/site-specific/researchfitedu/camid/documents/1411.0_Digital_ Twin_White_Paper_Dr_Grieves.pdf (accessed on 2 May 2018).

90. Tao, F.; Zhang, M. Digital Twin Shop-Floor: A New Shop-Floor Paradigm towards Smart Manufacturing. IEEE Access 2017, 5, 20418-20427. [CrossRef]

91. Mortensen, S.T.; Chrysostomou, D.; Madsen, O. A novel framework for virtual recommissioning in reconfigurable manufacturing systems. In Proceedings of the 22nd IEEE International Conference on Emerging Technologies and Factory Automation (ETFA), Limassol, Cyprus, 12-15 September 2017; pp. 1-4.

92. Haag, S.; Anderl, R. Digital twin-Proof of concept. Manuf. Lett. 2018, 15, 64-66. [CrossRef]

93. Zhang, H.; Liu, Q.; Chen, X.; Zhang, D.; Leng, J. A digital twin-based approach for designing and decoupling of hollow glass production line. IEEE Access 2017, 5, 26901-26911. [CrossRef]

94. Wagner, C.; Grothoff, J.; Epple, U.; Drath, R.; Malakuti, S.; Grüner, S.; Hoffmeister, M.; Zimermann, P. The role of the Industry 4.0 asset administration shell and the digital twin during the life cycle of a plant. In Proceedings of the IEEE International Conference on Emerging Technologies and Factory Automation (ETFA), Limassol, Cyprus, 12-15 September 2017; pp. 1-8.

95. Zhuang, C.; Liu, J.; Xiong, H. Digital twin-based smart production management and control framework for the complex product assembly shop-floor. Int. J. Adv. Manuf. Technol. 2018, 96, 1149-1163. [CrossRef]

96. Vachálek, J.; Bartalský, L.; Rovný, O.; Šišmišová, D.; Morháč, M.; Lokšík, M. The Digital Twin of an Industrial Production Line Within the Industry 4.0 Concept. In Proceedings of the 21st International Conference on Process Control, Strbske Pleso, Slovakia, 6-9 June 2017; pp. 258-262.

97. Schluse, M.; Priggemeyer, M.; Atorf, L.; Rossmann, J. Experimentable Digital Twins-Streamlining Simulation-Based Systems Engineering for Industry 4.0. IEEE Trans. Ind. Inform. 2018, 14, 1722-1731. [CrossRef]

98. Uhlemann, T.H.J.; Lehmann, C.; Steinhilper, R. The Digital Twin: Realizing the Cyber-Physical Production System for Industry 4.0. Procedia CIRP 2017, 61, 335-340. [CrossRef]

99. Cai, Y.; Starly, B.; Cohen, P.; Lee, Y.S. Sensor Data and Information Fusion to Construct Digital-twins Virtual Machine Tools for Cyber-physical Manufacturing. Procedia Manuf. 2017, 10, 1031-1042. [CrossRef]

100. Wang, K.S.; Li, Z.; Braaten, J.; Yu, Q. Interpretation and compensation of backlash error data in machine centers for intelligent predictive maintenance using ANNs. Adv. Manuf. 2015, 3, 97-104. [CrossRef]

101. Yan, J.; Meng, Y.; Lu, L.; Li, L. Industrial Big Data in an Industry 4.0 Environment: Challenges, Schemes, and Applications for Predictive Maintenance. IEEE Access 2017, 5, 23484-23491. [CrossRef]

102. Temer, E.; Pehl, H.-J. Moving Toward Smart Monitoring and Predictive Maintenance of Downhole Tools Using the Industrial Internet of Things IIoT. In Proceedings of the SPE Abu Dhabi International Petroleum Exhibition \& Conference, Abu Dhabi, UAE, 13-16 November 2017.

103. Italia, B.; Martinelli, S. SPE-183283-MS Smart Actuators: A Predictive Maintenance Strategy to Achieve Cost-Saving Targets. In Proceedings of the SPE Abu Dhabi International Petroleum Exhibition \& Conference, Abu Dhabi, UAE, 7-10 November 2016.

104. Zavoda, F.; Lemire, R.; Abbey, C. Implementing predictive distribution maintenance using a universal controller. In Proceedings of the IEEE PES T\&D Conference and Exposition, Chicago, IL, USA, 14-17 April 2014; pp. 1-5.

105. Zarte, M.; Wunder, U.; Pechmann, A. Concept and first case study for generic predictive maintenance simulation in AnyLogic ${ }^{\mathrm{TM}}$. In Proceedings of the 43rd Annual Conferenec of the IEEE Industrial Electronics Society, Beijing, China, 29 October-1 November 2017; pp. 3372-3377.

106. Borgi, T.; Hidri, A.; Neef, B.; Naceur, M.S. Data analytics for predictive maintenance of industrial robots. In Proceedings of the 2017 International Conference on Advanced Systems and Electric Technologies (IC_ASET), Hammamet, Tunisia, 14-17 January 2017; pp. 412-417.

107. Tsai, M.; Ko, P. On-line condition monitoring of servo motor drive systems by HHT in Industry 4.0. J. Chin. Inst. Eng. 2017, 40, 572-584. [CrossRef]

108. Amith, C.A.; Oommen, J.M.; Babu, J.; Paul, T.; Sankar, V. Predictive analysis for industrial maintenance automation and optimization using a smart sensor network. In Proceedings of the International Conference on Next Generation Intelligent Systems (ICNGIS), Kottayam, India, 1-3 September 2016; pp. 1-5.

109. Lao, L.; Ellis, M.; Christofides, P.D. Smart manufacturing: Handling preventive actuator maintenance and economics using model predictive control. AICHE J. 2014, 60, 2179-2196. [CrossRef] 
110. Liu, Y.; Shen, J. Research on equipment predictive maintenance strategy based on big data technology. In Proceedings of the International Conference on Intelligent Transportation, Big Data and Smart City (ICITBS), Halong Bay, Vietnam, 19-20 December 2015; pp. 641-644.

111. Sayed, M.S.; Lohse, N.; Søndberg-jeppesen, N.; Madsen, A.L. Diagnostics and Predictive Maintenance Using Smart Manufacturing Devices. In Proceedings of the 13th IEEE International Conference on Industrial Informatics (INDIN), Cambridge, UK, 22-24 July 2015.

112. Civerchia, F.; Bocchino, S.; Salvadori, C.; Rossi, E.; Maggiani, L.; Petracca, M. Industrial Internet of Things monitoring solution for advanced predictive maintenance applications. J. Ind. Inf. Integr. 2017, 7, 4-12. [CrossRef]

113. Brennan, R. Performance comparison and analysis of reactive and planning-based control architectures for manufacturing. Robot. Comput. Integr. Manuf. 2000, 16, 191-200. [CrossRef]

114. Weiss, M.; Zilch, A.; Schmeiler, F. Industrie 4.0 Status Quo und Entwicklungen in Deutschland. 2014. Available online: http://research.isg-one.de/company/press/releases/pressrelease/grosseanwenderstudie-zu-industrie-40-in-deutschland-hohe-potenziale-aber-auch-unsicherheit-und-unklareverantwortungen.html (accessed on 2 September 2014).

(C) 2018 by the authors. Licensee MDPI, Basel, Switzerland. This article is an open access article distributed under the terms and conditions of the Creative Commons Attribution (CC BY) license (http://creativecommons.org/licenses/by/4.0/). 